\title{
O impacto das cooperativas na produção agropecuária brasileira: uma análise econométrica espacial
}

\author{
The impact of cooperatives on Brazilian agricultural \\ production: a spatial econometric analysis
}

\author{
Mateus de Carvalho Reis Neves ${ }^{1}$ (D), Lucas Siqueira de Castro² (D) e \\ Carlos Otávio de Freitas ${ }^{2}$
}

\begin{abstract}
Resumo: Como importantes elos de ligação entre os produtores e o mercado, e respondendo direta ou indiretamente por relevante parte do Produto Interno Bruto agropecuário nacional, as cooperativas carecem de estudos que mensurem o quanto são capazes de influenciar a produção no meio rural, considerando as diferenças regionais brasileiras. Assim, este trabalho visou avaliar a existência e a magnitude do efeito das cooperativas na produção agropecuária das regiões brasileiras. Para tanto, foi construída uma função de produção, tendo as cooperativas como um fator deslocador da função de produção, considerando correção espacial, em termos municipais, para as regiões brasileiras. Os resultados evidenciam dependência espacial nos dados utilizados, justificando a abordagem metodológica utilizada neste trabalho. Verificou-se efeito positivo do cooperativismo no Valor Bruto da Produção da agropecuária nos municípios das regiões Sudeste, Centro-Oeste e Sul, ao passo que se notou influência restritiva da associação às cooperativas no Norte e Nordeste do País. Conclui-se, portanto, que a expansão do cooperativismo pelas regiões não foi um processo homogêneo, havendo ainda um longo caminho a ser percorrido para que se tenham níveis mais elevados de cooperação no meio rural brasileiro.
\end{abstract}

Palavras-chaves: Cooperativismo, econometria espacial, função de produção.

Data de submissão: 27 de outubro de 2017. Data de aceite: 28 de outubro de 2018.

1. Universidade Federal de Viçosa (UFV). Viçosa (MG), Brasil. E-mail: mateus.neves@ufv.br

2. Universidade Federal Rural do Rio de Janeiro (UFRRJ). Seropédica (RJ), Brasil. E-mails: lucancastro@hotmail.com; carlos.freitas87@gmail.com 


\begin{abstract}
Cooperatives are important links between producers and the market, responding directly or indirectly for a relevant portion of the agricultural Gross Domestic Product. There is a lack of studies that measure how much cooperatives influence production in the rural environment, considering Brazilian regional differences. Thus, the objective is to identify the influence of cooperatives in the agricultural production of Brazilian regions. Therefore, a production function considering cooperatives as one of its inputs was constructed, considering a spatial correction at the municipal level for Brazilian regions. The results show that there is spatial dependence on the data used, justifying the methodological approach used in this work. There was a positive effect of cooperatives on the Gross Value of Agricultural Production in the municipalities of the Southeast, Center-West and South, while the restrictive influence of the cooperative association in the North and Northeast was noted. Therefore, the expansion of cooperatives throughout the regions was not a homogeneous process, and there is still a long way to go in order to have higher levels of cooperation in the Brazilian countryside.
\end{abstract}

Keywords: Cooperatives, spatial econometrics, production function.

Classificação JEL: Q13, C21.

\section{Introdução}

As cooperativas ${ }^{1}$ no meio rural são constituídas, majoritariamente, por produtores rurais associados, que buscam, com estas organizações, atender aos anseios relacionados às suas atividades. No Brasil, segundo dados do último Censo Agropecuário, tais organizações respondem por, aproximadamente, $41 \%$ do Valor Bruto da Produção (VBP) agropecuária (Instituto Brasileiro de Geografia e Estatística, 2016), sendo meios de coordenação dos atores no setor primário da economia e importantes vias de acesso dos produtores ao mercado.

Embora relevantes no cenário agrícola, ainda são poucos os trabalhos que se dedicam a avaliar, para todo o Brasil, a influência das cooperativas agropecuárias sob a ótica econômica e produtiva. Internacionalmente, autores como McNamara et al. (2001), Folsom (2003), Zeuli et al. (2003), Zeuli \& Deller (2007), Rodrigo (2012), Cazzuffi (2013) e Jardine et al. (2014) fizeram avaliações, mesmo que locais, sobre os efeitos econômicos das cooperativas. Tais estudos levaram em consideração os impactos das cooperativas, entre outros pontos, em termos do impacto no Valor da Produção ou no Produto Interno

1 Embora a palavra "cooperativa" possa ser aplicada a diferentes tipos de atividades desenvolvidas de forma coletiva, o termo é usado neste trabalho para descrever um modelo de negócio democraticamente controlado e gerido por seus membros. Em muitos países, como no Brasil, as cooperativas são legalmente definidas como um tipo específico de corporação. Como tal, estão sujeitas à legislação federal específica (Zeuli \& Radel, 2005).
Bruto global ou de setores específicos ${ }^{2}$. Entretanto, tais estudos não consideraram as cooperativas interagindo com outros insumos em uma função de produção para a agricultura brasileira.

Todavia, estudos que abordem o cooperativismo na agricultura brasileira devem ponderar sobre suas especificidades regionais, refletidas no meio rural. Estudos como os de Helfand \& Brunstein (2001), Silva et al. (2003), Fundação Getulio Vargas \& Instituto Brasileiro de Economia (2010), Kageyama et al. (2013), Helfand et al. (2014) e Belik (2015) evidenciam pontos que reforçam as diferenças nos padrões produtivos e de desigualdades no campo, que já não mais ficam restritas à dicotomia latifúndio vs. pequena propriedade, havendo heterogeneidades profundas mesmo entre os estabelecimentos menores.

O fato de existirem diferentes áreas no Brasil que atuam no cultivo de um mesmo produto, neste caso relacionado à agropecuária, mesmo sob variadas condições existentes (produção ou técnica), suscita o aspecto de interdependência, que pode levar ao transbordamento de ações que influenciem indivíduos (independente da forma jurídica) em diferentes níveis de desagregação geográfica (autocorrelação/dependência espacial), gerando competição espacial (Castro et al., 2015).

2 Trabalhos desta natureza podem ser consultados em Zeuli \& Deller (2007) e Uzea \& Duguid (2015). Ambos fizeram análises das nuances que envolvem a pesquisa de impacto econômico de cooperativas, destacando as metodologias empregadas nestes estudos, recorrentemente, análises de matrizes insumo-produto. 
Isto posto, buscou-se identificar neste trabalho a influência das cooperativas na produção agropecuária das regióes brasileiras, marcadamente heterogêneas em termos produtivos, socioeconômicos e até mesmo em termos do "capital social" no sentido preconizado por Putnam (1995). Para tanto, foi empregada uma função de produção com correções espaciais, compreendendo os insumos comumente utilizados na produção rural, sendo a variável de interesse, associação a cooperativas, considerada no processo produtivo.

O artigo é composto, além desta introdução, por mais quatro seções. A segunda seção aborda o cooperativismo no Brasil rural. Já a terceira seção conta com a estratégia empírica utilizada, bem como com a fonte de dados. A quarta seção traz a discussão sobre os resultados. A última parte trata das considerações finais acerca do problema estabelecido.

\section{Cooperativismo no Brasil rural - relevância e heterogeneidades}

A literatura relativa à economia das organizações explica a existência das cooperativas agropecuárias por sua habilidade de: a) engendrar economias de escala; b) acessar novos mercados, inclusive internacionais; $\mathrm{c}$ ) reduzir custos por meio da integração vertical; d) diminuir riscos em ações conjuntas; e) possibilitar aos cooperados acessar e adotar tecnologias e insumos via serviços de assistência técnica e f) permitir aos associados desenvolver poder de barganha por melhores preços (Bonus, 1986; Sexton, 1986; Staatz, 1987; Hansmann, 1988, 1996; Sexton \& Iskow, 1988; Bialoskorski Neto, 2000; Valentinov, 2007).

Essas características ajudam a explicar a propagação do cooperativismo em vários países, como ilustram alguns exemplos: no Japão, as cooperativas agropecuárias congregam em torno de $90 \%$ de todos os agricultores, enquanto no Canadá e Noruega, quatro em cada 10 agricultores são cooperados. Ainda, na Nova Zelândia, as cooperativas respondem por $95 \%$ do mercado de laticínios por $22 \%$ do PIB (Namorado, 2013).

No Brasil, a introdução do modelo cooperativo remonta ao final do século XIX, com algumas experiências em São Paulo e Pernambuco. A partir de 1902, surgem as primeiras cooperativas de crédito rural do modelo Raiffeisen, em Nova Petrópolis (RS), sendo, em 1907, criadas as primeiras cooperativas agropecuárias no estado de Minas Gerais. Tais cooperativas agrícolas, ao longo da primeira metade do século $X X$, se mostraram as mais pujantes em termos de volume de negócio, sendo, ao mesmo tempo, as principais responsáveis pela difusão do ideário cooperativista no País (Silva et al., 2003).

Pinho (1996) e Presno (2001) afirmam que, dadas as suas características intrínsecas, as cooperativas foram fomentadas pelo governo como importantes instrumentos para a aplicação e disseminação de políticas públicas orientadas ao setor agrário (assistência técnica, acesso ao mercado, entre outras), desde a década de 1930, mesmo que, por vezes, a criação de cooperativas engendradas por estas políticas não fosse objeto de análise prévia.

No entanto, ao longo da década de 1980, o arrefecimento da atividade econômica nacional e das políticas intervencionistas do Estado atreladas às cooperativas, somado à crescente demanda por práticas de gestão mais modernas, levaram ao desaparecimento de muitas cooperativas agropecuárias, resultando num crescente sentido de receio quanto a tais organizações (Pinho, 1992; Presno, 2001; Bialoskorski Neto, 2005).

Após superarem momentos mais agudos de crise nas décadas de 1980 e 1990, as cooperativas brasileiras vinculadas às atividades agropecuárias formam, atualmente, um dos mais proeminentes ramos do cooperativismo, retomando papel importante na coordenação de muitos aspectos da cadeia agroalimentar. Segundo a Organização das Cooperativas Brasileiras (Organização das Cooperativas Brasileiras, 2013), entre suas filiadas, as cooperativas agropecuárias perfaziam um total de $23,5 \%$ dentre todas as cooperativas ativas em $2013^{3}$.

Ainda de acordo com os dados de Organização das Cooperativas Brasileiras (2012, 2013, 2015, 2017), Figura 1, depreende-se que o movimento cooperativista agropecuário, depois de registrar queda no número de cooperativas até 2004, ganhou força a partir de então, mantendo-se razoavelmente estável, com um discreto crescimento no número de associados, que ultrapassava, em 2013, a marca de um milhão de pessoas. Em termos de

\footnotetext{
Além da OCB, há ainda outras organizações que congregam cooperativas ligadas diretamente à agricultura, como a União Nacional das Cooperativas da Agricultura Familiar e Economia Solidária (Unicafes) e a Confederação das Cooperativas de Reforma Agrária no Brasil (Concrab). Estas organizações têm números relevantes de cooperativas e associados, caso da Unicafes, que, em 2012, tinha 789 cooperativas filiadas, com total de 365.145 associados, segundo dados da própria organização.
} 
Figura 1. Evolução do número de cooperativas filiadas à OCB e seus associados, ramo agropecuário, 2002 a 2015

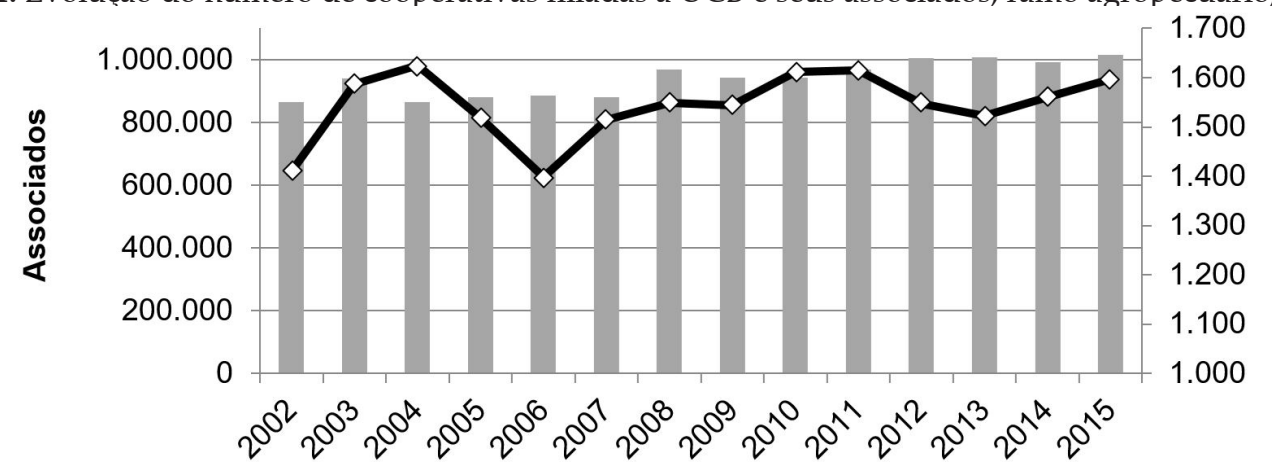

1.700

1.500

$\frac{2}{\pi}$
$\frac{1}{\pi}$
$\frac{\pi}{2}$
$\frac{0}{0}$
0

Associados $\rightarrow$ Cooperativas

Fonte: Elaborada pelos autores com dados de Organização das Cooperativas Brasileiras (2012, 2013, 2015, 2017).

Tabela 1. Percentuais de estabelecimentos agropecuários, estabelecimentos agropecuários associados a cooperativas e Valor Bruto da Produção (VBP), regiões brasileiras, 2006

\begin{tabular}{lcccccc}
\hline & Norte & Nordeste & Sudeste & Sul & Centro Oeste & Brasil \\
\hline Estabelecimentos $(\%)^{1}$ & 9 & 47 & 18 & 19 & 7 & 100 \\
Valor Bruto da Produção $(\%)^{1}$ & 6 & 17 & 32 & 27 & 18 & 100 \\
Associação a cooperativas $(\%)^{2}$ & 3,8 & 4,3 & 18 & 31,9 & 12 & 14,4 \\
\hline
\end{tabular}

Fonte: Elaborada pelos autores com dados de Instituto Brasileiro de Geografia e Estatística (2016).

Notas: ${ }^{1}$ Percentuais obtidos considerando a participação de cada região no total. ${ }^{2}$ Percentual obtido considerando a proporção de estabelecimentos associados em cada região e no Brasil.

participação econômica, as cooperativas agropecuárias alcançaram papel de destaque: em 2013, eram responsáveis por 340 mil postos de trabalho diretos e respondiam por $6 \%$ do PIB nacional.

Entretanto, a distribuição destas cooperativas pelo território nacional é um tanto heterogênea, refletindo as marcadas diferenças regionais brasileiras. Tal disparidade fica evidenciada na análise dos dados da Tabela 1.

Segundo dados do Censo Agropecuário de 2006, em média, $14,4 \%$ dos estabelecimentos rurais eram associados a cooperativas. Além disso, é possível notar uma disparidade marcante entre as regióes do País, não somente no que diz respeito à consolidação do movimento cooperativista, mas também no que se refere ao número de estabelecimentos agropecuários e ao VBP agropecuário. Tais diferenças regionais são, segundo Helfand \& Brunstein (2001), recorrentes nas análises da agricultura brasileira, como reflexo de condições diversas acerca da infraestrutura, mercado de trabalho, distância dos centros consumidores e outros pontos, aos quais se acrescentam, para o caso específico do processo de cooperação, questões culturais e históricas.

Em 2006, a região Norte tinha apenas 3,8\% de seus estabelecimentos rurais associados a cooperativas.
No Nordeste, em que pouco mais de $4 \%$ dos estabelecimentos eram cooperados, percebe-se o grande contraste entre a proporção de estabelecimentos (47\%) e a participação destes no VBP (17\%). Por outro lado, destacam-se como tendo maior percentual de estabelecimentos cooperados as regiões Sul e Sudeste, com, respectivamente, 31,9\% e $18 \%$ de estabelecimentos associados, sendo também estas as regiões com maior participação no VBP agropecuária nacional, o que pode levar ao questionamento se, de fato, as cooperativas têm participação efetiva no auxílio à produção dos estabelecimentos agropecuários.

Apesar de não explicar toda a sua magnitude, tais diferenças regionais observadas no cooperativismo brasileiro foram motivadas pela forte influência de imigrantes - alemães, italianos e japoneses - instalados nas regiões Sul e Sudeste, muitos dos quais já traziam algumas experiências relativas à prática do associativismo, tendo incutido a cultura e a educação cooperativa, além de um elevado nível de capital social ${ }^{4}$, servindo como alicerce para a estruturação do cooperativismo em bases competitivas (Silva et al., 2003).

4 Este capital pode ser compreendido, como define Putnam (1995), como uma coligação de elementos, quais sejam, confiança, reciprocidade, coesão social e civismo. 
Adicionalmente, o fomento estatal, citado anteriormente, contribuiu para acentuar estas discrepâncias regionais, ao ter seu maior fluxo direcionado, em décadas passadas, à região Sudeste (Duarte, 1986).

\section{Estratégia empírica}

A estratégia empírica a ser seguida para identificar a influência das cooperativas na produção agropecuária das regiões brasileiras consiste em combinar uma função de produção, subseção 3.1, com técnicas da econometria espacial, subseção 3.2. A fonte e a forma como foram tratados os dados estão na subseção 3.3.

\subsection{Função de produção}

Pode-se tomar uma relação funcional de produção genérica $Y=f(L, K, T, \ldots)$, como descrita por Humphrey (1997), em que $Y$ é a produção resultante da combinação dos fatores trabalho $L$, do capital $K$, da terra $T$ etc. e adaptá-la ao objetivo deste trabalho:

$Y_{i}=f\left(L_{i}, T_{i}, I_{i}, K_{i}, C_{i}\right)$

em que $Y_{i}$ é o valor bruto da produção agropecuária, $L_{i}$ diz respeito às unidades de trabalho utilizadas, $T_{i}$ é a área cultivada, $I_{i}$ representa o valor gasto com insumos, $K_{i}$ refere-se às benfeitorias e $C_{i}$ é a adesão a cooperativas, sendo estas variáveis referentes aos estabelecimentos agropecuários do município ${ }^{i}$.

O papel das cooperativas nesta função não é o de fator produtivo direto, mas, sim, o de, teoricamente, atuar como deslocadoras da função de produção ${ }^{5}$, permitindo aos produtores rurais acesso a novos insumos e mercados, por exemplo. Como definido por Curi (1997), investimentos em acesso à informação, parques industriais mais modernos, assistência técnica e extensão rural podem ser entendidos como elementos provedores da modernização na agricultura. Entende-se que as cooperativas podem ser promotoras destes elementos, levando a alterações no patamar da agropecuária brasileira.

A adequação teórica desta relação funcional foi proposta por Cobb \& Douglas (1928). A forma funcional

\footnotetext{
O que se busca neste trabalho é fazer uma análise cross-section baseada na importância da tecnologia, como no modelo de inovação induzida de Hayami \& Ruttan (1971), em que a tecnologia é vista como uma variável endógena no processo de crescimento da produção.
}

Cobb-Douglas é comumente utilizada, sendo um modelo simples associado a um número de propriedades restritas, como a elasticidade e os retornos de escala constantes (Coelli et al., 1998). Apesar de suas limitações, de acordo com Baumol (1977) e Castro (2002), a especificação do tipo Cobb-Douglas é dotada de facilidade de interpretação dos resultados - os coeficientes estimados são as próprias elasticidades do modelo - e de boas qualidades estatísticas em termos de aderência aos dados, sendo atrativa para o processo de estimação, já que tem a propriedade de se tornar linear quando reescrita em termos do ajuste logarítmico de suas variáveis:

$\ln Y_{i}=\ln A+\alpha \ln L_{i}+\beta_{1} \ln T_{i}+\beta_{2} \ln I_{i}+\beta_{3} \ln K_{i}+\beta_{4} \ln C_{i}$

Sob esta forma, parcimoniosa em termos da quantidade de coeficientes a serem estimados, evitando-se, assim, possível multicolinearidade, são acrescidas as características espaciais do modelo final utilizado neste trabalho.

Como as perspectivas trabalhadas envolvem desagregações geográficas em nível municipal, tornou-se necessário considerar a possibilidade da ocorrência de dependência espacial entre as regiões. Em outras palavras, características de municípios vizinhos poderiam afetar o município em análise e vice-versa, o que inviabilizaria a interpretação dos resultados obtidos por meio de Mínimos Quadrados Ordinários (MQO).

\subsection{Aspectos espaciais}

Para a investigação pretendida, tem-se como primeiro passo a análise exploratória dos dados espaciais (Aede). Esta Aede foi desenvolvida por meio dos testes de I de Moran, que consideram tanto perspectivas globais quanto locais acerca das variáveis.

A proposição de Moran (1948) para o seu coeficiente de autocorrelação espacial global, do tipo produto-cruzado, é dada algebricamente como:

$I=\frac{n}{S_{0}} \frac{z^{\prime} W z}{z^{\prime} z}$

em que $n$ é o número de municípios; $z$ corresponde aos valores da variável de interesse padronizada no município de interesse; e $W z$, aos valores médios da variável de interesse padronizada nos municípios vizinhos (levando em consideração a matriz de ponderação $W$ ). Neste caso, o numerador representa a autocovariância espacial, composta pelo produto cruzado $z W z$.

Discorrendo sobre o valor esperado do teste, dado pela relação [1/(n-1)], valores obtidos que ultrapassem 
tal valor indicam autocorrelação espacial positiva, bem como valores menores que o da relação sugerem autocorrelação espacial negativa.

Espera-se que, com o teste de Moran, possam ser obtidos três tipos de informações. A primeira remete ao nível de significância, em que o teste informa se os dados estão distribuídos aleatoriamente ou não; em outras palavras, se tais dados apresentam algum tipo de padrão espacial.

A segunda é dada pelo sinal da estatística. Caso este sinal seja positivo, desde que a estatística seja significativa, há indícios de que os dados são concentrados na região (quadrante de análise) e, caso negativo, estes dados estão dispersos. A terceira e última trata da magnitude do resultado. Quanto mais próximo de 1 for o valor obtido, maior será a concentração, e quanto mais perto de -1, mais dispersos estarão dados.

Proposto por Anselin (1995), o Lisa (Local Indicator of Spatial Association), por sua vez, é um indicador capaz de captar padrões locais de autocorrelação espacial, caso se cumpram duas condições: indicar clusters espaciais estatisticamente significativos, além de ter a propriedade na qual o somatório dos indicadores locais para as regiões seja proporcional ao indicador de autocorrelação espacial global referente.

Matricialmente, o I de Moran local para uma variável qualquer padronizada, datada em um município $i, Z_{i}$, em que o indicador abrange apenas os vizinhos indicados neste município, é dado por:

$I_{i}=Z_{i} \sum_{j=I}^{J} w_{i j} z_{j}$

Diferente do I de Moran Global, que apresenta apenas um resultado, o I de Moran Local apresenta um resultado para cada município estudado, neste caso. Tal densidade de informações pode ser compilada em mapas para facilitar a interpretação das respostas.

O mapa de clusters Lisa, por exemplo, mescla as informações obtidas no diagrama de dispersão de Moran com o mapa de significância das medidas do $I$ de Moran local, dividindo o resultado entre quatro regiões estatisticamente significantes, sendo estas os vetores alto-alto, baixo-baixo, baixo-alto e alto-baixo. Para este estudo será utilizada a análise deste mapa em específico.

O segundo passo da análise espacial constitui-se da estimação convencional de modelos por MQO. O teste de Moran Global, neste caso, também foi aplicado aos resíduos do modelo $\mathrm{MQO}$, com o objetivo de verificar a existência da autocorrelação espacial. Caso seja encontrado, o modelo a ser desenvolvido, terceiro passo, deve levar em consideração formas de eliminar este problema pela inclusão de interações / defasagens espaciais. Testes mais específicos, como o do multiplicador de Lagrange e suas versões robustas, são capazes de apontar o tipo de defasagem espacial a ser incluída no modelo estimado ${ }^{6}$.

Desta maneira, a especificação do modelo espacial pode ser observada nas equações (5a) e (5b):

$y_{i t}=\alpha+\rho W y_{i t}+X_{i t} \beta+W X_{i t} \tau+\xi_{i t}$

$\xi_{i t}=\lambda W \xi_{i t}+\varepsilon_{i t}$

em que $\tau, \rho$ e $\lambda$ são coeficientes a serem estimados; $y$ representa a variável dependente, valor bruto da produção agropecuária; $X$ é um vetor composto por variáveis de controle, definidas na subseção anterior; $W$ são matrizes de ponderações espaciais; e $\xi$ corresponde ao termo de erro.

Impondo restrições aos parâmetros espaciais da equação (5), são determinados vários modelos espaciais. Com a imposição de que $\tau=\lambda=0$ e $\rho \neq 0$, alcança-se o modelo SAR (defasagem espacial da variável dependente); com $\tau=\rho=0$ e $\lambda \neq 0$, dispõe-se do modelo SEM (defasagem espacial do termo de erro); $\operatorname{com} \lambda=0$, $\tau \neq 0 e \rho \neq 0$, atinge-se o modelo SDM (defasagem espacial da variável dependente e das variáveis de controle); fazendo com que $\rho=0, \tau \neq 0 e \lambda \neq 0$, consegue-se o modelo SDEM (defasagem espacial do termo de erro e das variáveis de controle); por fim, $\operatorname{com} \rho=\lambda=0$ e $\tau \neq 0$, tem-se o modelo SLX (defasagem espacial das variáveis de controle) ${ }^{7}$.

Adicionalmente às informações sobre áreas contíguas concedidas, os modelos espaciais também geram coeficientes de correlações parciais entre variáveis. Lesage \& Pace (2009) mostraram ser possível dividir estes coeficientes, apresentando-os na forma de efeitos direto, indireto e total. Para tanto, é preciso que a dependência espacial seja observável, como em modelos dos tipos SAR, SDM e SLX. Mostrando-se possível, a aplicação da técnica melhorará a qualidade das informações sobre a influência das cooperativas na produção agropecuária das regiões brasileiras.

6 A literatura relaciona outros procedimentos que facilitam a estimação de modelos espaciais. Entre os comumente empregados, há o clássico, o híbrido, o de Hendry (Florax et al., 2003) e o completo (Almeida, 2012).

7 Caso os parâmetros espaciais da equação (5) sejam nulos, o modelo obtido seria o MQO convencional. Mais informações sobre os modelos espaciais citados podem ser encontradas nos trabalhos de Lesage (2008) e Anselin (2013). 


\subsection{Fonte e considerações sobre os dados}

Os dados utilizados neste trabalho têm como fonte o Censo Agropecuário Brasileiro de 2006, último ano em que um levantamento desta natureza foi feito (Instituto Brasileiro de Geografia e Estatística, 2016). O período de referência deste censo compreendeu $1^{\circ}$ de janeiro a 31 de dezembro de 2006, tratando-se de uma fonte de dados cross-section (Instituto Brasileiro de Geografia e Estatística, 2016). É importante enfatizar que o modelo discutido nas seções anteriores não é estimado com dados em nível de fazenda, ou seja, com o uso de microdados.

Os resultados do Censo Agropecuário 2006 são divulgados em nível de unidades administrativas, os municípios, de modo a agregar os estabelecimentos agropecuários. Esta agregação é feita para preservar a identidade dos produtores rurais ${ }^{8}$. Por este motivo, os dados utilizados para a operacionalização da função lucro restrita tiveram como unidades básicas de análise do Censo Agropecuário os estabelecimentos agropecuários, agregados em municípios das macrorregiões brasileiras. Por "estabelecimento agropecuário", entende-se, segundo o Instituto Brasileiro de Geografia e Estatística (2016, p.7):

"[Estabelecimento agropecuário é toda] unidade de produção dedicada, total ou parcialmente, a atividades agropecuárias, florestais e aquícolas, subordinada a uma única administração: a do produtor ou a do administrador. Independente de seu tamanho, de sua forma jurídica ou de sua localização em área urbana ou rural, tendo como objetivo a produção para subsistência e/ ou para venda, constituindo-se assim numa unidade recenseável."

Considerando os 5.500 municípios que compõem as unidades de análise deste trabalho, tem-se que este é o número máximo de observações. De acordo com Helfand et al. (2015), a agregação dos dados leva a se assumir a homogeneidade entre cada uma das observações agregadas. Cada uma das 5.500 "fazendas representativas" ${ }^{\prime \prime}$ reflete o comportamento médio de um

8 De acordo com o que preconiza a legislação específica sobre os censos no Brasil, para toda a operação são mantidas as características de obrigatoriedade e confidencialidade referidas às informações censitárias, que se destinam apenas para uso estatístico e não podem ser objeto de certidão nem prova jurídica (Instituto Brasileiro de Geografia e Estatística, 2016).

9 Podem ser consultados Nerlove \& Bachman (1960), Barker \& Stanton (1965) e Sharples (1969) para discussões sobre os desdobramentos do emprego de "fazendas representativas" em estudos sobre economia rural. grupo de estabelecimentos rurais em um determinado município. Estes 5.500 municípios englobavam 5.175.636 estabelecimentos agropecuários, segundo dados de Instituto Brasileiro de Geografia e Estatística (2016).

Para a estimação da função de produção, o valor bruto da produção em 2006 (produção), em Reais, foi definido como a variável produto. No tocante aos fatores de produção, eles foram definidos pelas seguintes variáveis: área produtiva (terra), compreendendo a soma, em hectares (ha), das áreas de lavoura, pecuária e agrossilvicultura, representando uma proxy do fator terra; valor total, em Reais, dos bens dos estabelecimentos agropecuários (capital), como proxy para bens de capital; soma do número de unidades de trabalho (ut) familiar e contratada (trabalho $)^{10}$, sendo uma proxy do fator trabalho; e a despesa realizada não remuneradora de fator produtivo (insumos), referindo-se ao somatório, em reais, dos gastos com corretivos do solo, adubos, agrotóxicos, medicamentos para animais, sementes e mudas, sal/ ração, combustível e energia, representando uma proxy dos insumos.

A variável de interesse, associação a cooperativas, foi considerada por conta das evidências de que estas organizações seriam capazes de influenciar nas escolhas ótimas dos produtores rurais. Assim, tornou-se uma questão importante deste trabalho encontrar um modo de representar esta variável. Como o Censo Agropecuário de 2006 não foi acessado em nível de microdados, uma alternativa foi considerar o percentual de estabelecimentos agropecuários que responderam "sim" à pergunta "é associado à cooperativa?". Por consequência, esta variável foi representada pela divisão, em cada município,

10 Conforme a metodologia do Censo Agropecuário 2006, a unidade de trabalho (ut) familiar foi obtida pela soma do número de pessoas, homens ou mulheres, com laços de parentesco com 14 anos ou mais de idade, inclusive a pessoa que dirige o estabelecimento, mais a metade do número de pessoas com laços de parentesco menores de 14 anos, mais o número de empregados em "outra condição" com 14 anos ou mais de idade, mais a metade do número de empregados em 'outra condição' com menos de 14 anos de idade. Já a unidade de trabalho contratado foi obtida pela soma do número de homens e mulheres: empregados permanentes de 14 anos ou mais de idade, mais a metade do número de empregados permanentes com menos de 14 anos de idade, mais empregados parceiros de 14 anos ou mais de idade, mais a metade do número de empregados parceiros com menos de 14 anos de idade, mais o resultado da divisão do número de diárias pagas em 2006 por 260, e mais o resultado da divisão dos dias de empreitada por 260 (Instituto Brasileiro de Geografia e Estatística, 2016). 
Tabela 2. Estatísticas descritivas (x 1.000)

\begin{tabular}{lcccrr}
\hline & produção $\mathbf{( R \$ )}$ & trabalho $(\mathbf{u t})$ & terra $($ ha) & insumos (R\$) & capital (R\$) \\
\hline Média & $22.789,96$ & 2,16 & 55,58 & $8.530,78$ & $179.826,51$ \\
Desvio Padrão & $42.199,85$ & 2,47 & 123,89 & $40.929,58$ & $286.441,37$ \\
Mínimo & 0,00 & 0,00 & 0,00 & 0,00 & 16,90 \\
Máximo & $878.000,00$ & 32,31 & $4.986,19$ & $1.300 .000,00$ & $3.650 .000,00$ \\
Total & $125.344 .804,34$ & $11.901,20$ & $305.679,31$ & $46.919 .311,84$ & $989.045 .809,55$ \\
\hline
\end{tabular}

Fonte: Elaborada com base em dados de Instituto Brasileiro de Geografia e Estatística (2016).

do número de respostas positivas a esta questão pela quantidade total de estabelecimentos rurais existentes.

No Brasil, o cooperativismo tem, desde seu surgimento, uma forte inspiração nos princípios rochedaleanos ${ }^{11}$. Por este motivo, desde a primeira legislação acerca das cooperativas até a "Lei do Cooperativismo" (Lei n. 5.764/71), é possível notar a marcante inspiração em tais princípios, de acordo com Pinho (1992). Destarte, por imposição legal, as cooperativas têm livre entrada, salvo sua limitação técnica de receber mais membros. Igualmente, não há restrição à saída de cooperados. Porém, para que o produtor rural faça parte de uma cooperativa, é necessário que ele resida na região de atuação da mesma. Deste modo, a decisão de adesão a uma cooperativa por parte dos produtores rurais é complexa e envolve vários fatores, como a disponibilidade de cooperativas e de sociedades de capital que ofereçam serviços equivalentes, os preços praticados, além de aspectos culturais e históricos. Todos estes pontos influenciam o percentual de produtores rurais que optam por se associar a uma cooperativa.

Sabe-se da relevância em considerar as diferenças regionais do Brasil na análise da função de produção para os municípios, pois, conforme Buainain et al. (2007), além das condições naturais, o território brasileiro é heterogêneo, por outros fatores, como aqueles relativos à ocupação histórica. Tendo isto em mente, a regressão foi estimada considerando efeitos fixos em níveis regionais, na tentativa de controlar essa heterogeneidade espacial. Para tanto, interagiu-se a variável de interesse com

11 Em 1966, por ocasião do Congresso da Aliança Cooperativa Internacional em Viena, a redação dos "Princípios" dos Pioneiros de Rochdale (primeira cooperativa criada neste distrito inglês) ficou assim estabelecida: 1- Adesão livre; 2- Controle (ou gestão) democrático; 3- Distribuição das sobras: a) ao desenvolvimento da cooperativa; $b$ ) aos serviços comuns; c) aos cooperados, pro rata das operações; 4- Juros limitados ao capital; 5- Constituição de um fundo para educação e 6- Cooperação entre cooperativas, em planos local, regional, nacional e internacional. dummies para cada macrorregião do País (DN, DNE, DSE e $D C O$, com a região Sul como categoria base), as quais assumiam valor 1 quando o município pertencia àquela unidade da federação e valor 0 , caso contrário. Em vista disso, estas foram as variáveis inseridas no modelo para representar o nível de associação a cooperativas nos municípios de cada macrorregião brasileira.

Salienta-se que todas as agregações, geração de dados e análises foram feitas utilizando os softwares STATA $^{\circledR}$, Geoda $^{\circledR}$, GeodaSpace $^{\circledR}$ e $R^{\circledR}$.

\section{Resultados}

\subsection{Estatísticas descritivas}

Considerando as variáveis descritas anteriormente como aquelas utilizadas na estimação do modelo econométrico empregado neste trabalho, a Tabela 2 contém características gerais dos dados que as compõem. São apresentados os valores municipais para cada variável, ou seja, o valor médio da produção de R\$22.789.960,00 diz respeito à média do $\mathrm{VBP}$ agropecuária para os municípios brasileiros. Observam-se ainda, em média, 2.160 unidades de trabalho equivalente nos municípios do País.

Ainda com relação à Tabela 2, os valores totais de cada variável dizem respeito ao somatório dos dados para todos os 5.500 municípios brasileiros considerados. Assim, o VPB (produção) da agropecuária brasileira foi de aproximadamente R\$ 125 bilhões em 2006.

Com relação à variável de interesse, associação a cooperativas, já descrita na Tabela 1, é oportuno conhecer sua distribuição espacial pelo território brasileiro. Pela análise da Figura 2 observa-se que, na região Sul, tradicionalmente marcada pela proeminente presença de organizações cooperativas, há maior concentração destas organizações, com destaque para o noroeste do 
Figura 2. Distribuição espacial da proporção de estabelecimentos agropecuários associados a cooperativas nos

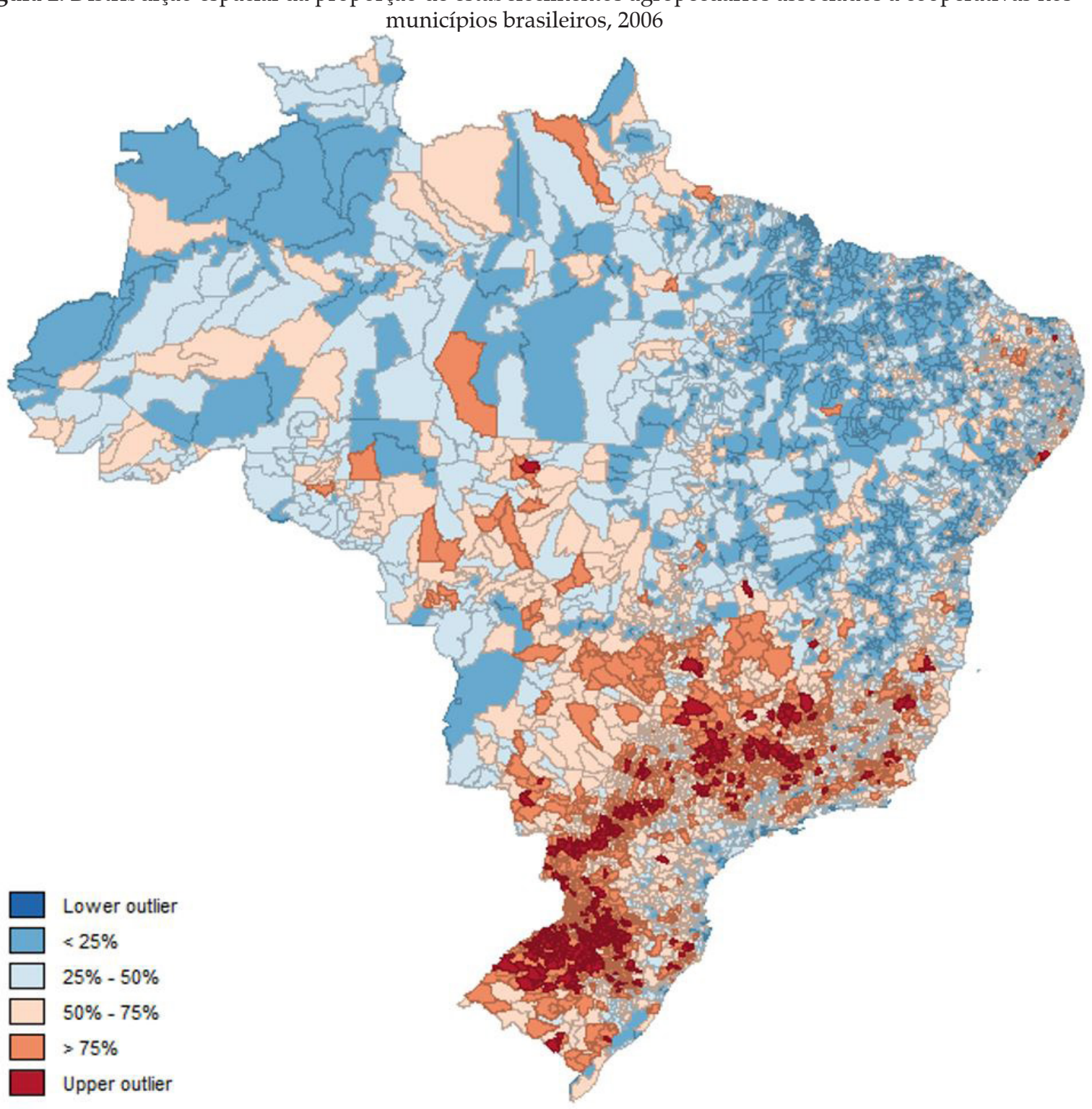

Fonte: Elaborada com base em dados de Instituto Brasileiro de Geografia e Estatística (2016).

Rio Grande do Sul e o oeste do Paraná, além do noroeste de Santa-Catarina, importantes regiões agropecuárias.

No Sudeste, que conta com média de $18 \%$ de estabelecimentos agropecuários associados a cooperativas, há uma concentração dos municípios com proporção de associados acima de 0,20 no Triângulo Mineiro, no sul de Minas Gerais, e no estado de São Paulo. O norte do estado do Rio de Janeiro, em menor grau, também tem municípios com elevada concentração de estabelecimentos cooperados. Os municípios das porções sul de Goiás e Mato Grosso do Sul também estão, em sua maioria, nos dois quantis superiores da proporção de estabelecimentos a cooperativas, sendo menos intensa a presença de municípios com as maiores taxas de associação a cooperativas na região Centro-Oeste. Já ao observar os municípios das regiões Norte e Nordeste do País, fica claro que a maior parte deles pertence aos três quantis inferiores de taxas de associação a cooperativas, com destaque para a baixa adesão a estas organizações nos estabelecimentos dos municípios dos estados do Ceará, Maranhão e Piauí, além de Amazonas e Roraima. 
Tabela 3. Estatística de I de Moran para as variáveis dependente e de controle

\begin{tabular}{ccccccc}
\hline Matriz & Variável & Valor & Média & Desvio Padrão & Z & P-valor \\
\hline k-4 & capital & 0,4115 & 0,0000 & 0,0090 & 45,9204 & $0,0000^{* * * *}$ \\
k-7 & trabalho & 0,3190 & 0,0000 & 0,0068 & 46,6213 & $0,0000^{* * * *}$ \\
k-2 & cooperativas & 0,7876 & 0,0000 & 0,0124 & 63,7351 & $0,0000^{* * * *}$ \\
k-2 & terra & 0,4337 & 0,0000 & 0,0124 & 35,0992 & $0,0000^{* * *}$ \\
k-5 & produção & 0,2264 & 0,0000 & 0,0081 & 28,1154 & $0,0000^{* * * *}$ \\
k-3 & insumos & 0,1282 & 0,0000 & 0,0103 & 12,5167 & $0,0000^{* * * *}$ \\
\hline
\end{tabular}

Fonte: Elaborada pelos autores.

Nota: * Significativo a $10 \% ; * *$ Significativo a $5 \% ; * * *$ Significativo a $1 \%$

\subsection{Análise espacial dos dados}

A Análise Exploratória de Dados Espaciais realizada sobre as variáveis dependente e de controle, conforme já estabelecido, foi dividida em duas partes: global e local. Em ambas as análises foi preciso determinar o tipo mais apropriado de matrizes de ponderações espaciais $(W)$. A escolha destas matrizes, para estes procedimentos, deu-se em função do procedimento de Baumont (2004) ${ }^{12}$.

$\mathrm{Na}$ avaliação global, as matrizes eleitas foram as do tipo $k$ vizinhos. A gradação das matrizes por variável encontra-se na Tabela 3, na qual também é possível observar os resultados do teste de Moran. Em geral, independentemente da variável analisada, os $p$-valores foram estatisticamente significativos a $1 \%$, indicando a existência de padrões espaciais nas variáveis selecionadas, em termos municipais, para o Brasil.

Descoberta a existência de autocorrelação espacial, os resultados também fornecem indícios para determinar a forma como estes padrões se manifestam. Os sinais dos coeficientes indicaram presença da dependência espacial positiva, a qual configura a concentração geográfica por dois modos: no primeiro, municípios com valores elevados de produção, por exemplo, farão divisa com municípios que apresentem valores análogos; no segundo, por sua vez, municípios com baixos valores de terra serão contíguos a municípios com características semelhantes.

No que diz respeito à investigação local, foi feita por meio dos mapas Lisa (Local Indicator of Spatial Association), operando matrizes do tipo $k-2$ vizinhos mais próximos. Neste caso, optou-se pela elaboração do mapa apenas

12 O procedimento consiste na realização de testes de autocorrelação espacial, como o I de Moran, sobre os resíduos do MQO. A opção pela matriz é feita com base no resultado de teste que apresentar a maior autocorrelação espacial estatisticamente significativa. Desta forma, o procedimento de Baumont (2004) impede a existência de vieses associados à forma como as matrizes espaciais são selecionadas. para a variável de interesse (associação a cooperativas), Figura 3, dada a limitação de espaço deste trabalho.

Pela análise da Figura 3, observa-se existência majoritária de apenas dois tipos de clusters, alto-alto e baixo-baixo, além de vários municípios cujos indicadores de autocorrelação espacial local não são estatisticamente significativos.

Nos clusters alto-alto, estão indicados municípios com altas taxas de associação a cooperativas (acima da média), vizinhos de municípios também com alto valor de associação a cooperativas. Este cluster se concentra nas macrorregiões Sudeste, Sul e Centro-Oeste, historicamente marcadas pela existência de um maior número de estabelecimentos rurais associados a cooperativas. Cooperativas fortes e abrangentes, que atuam em seu município-sede e também em municípios adjacentes, são comuns na região Sul do País, primordialmente nos estados do Paraná e de Santa Catarina, além das cooperativas receptadoras de leite do Sudeste (Neves \& Braga, 2015). Soma-se a isto o importante papel de cooperativas de crédito no fornecimento de crédito rural para muitos produtores destas regiões.

Por outro lado, os clusters do tipo baixo-baixo estão alocados no Norte e no Nordeste, sendo nesta última em maior quantidade, tratando-se ambas de regiões onde o cooperativismo ainda não é tão difundido como na região Centro-Sul do País. Este padrão é bastante similar ao estabelecido pela dispersão espacial da Figura 2.

\subsection{Efeito da associação a cooperativas}

Prosseguindo com a análise proposta na estratégia empírica, o modelo foi estimado, incialmente, por $\mathrm{MQO}$, com os resultados sendo reportados na Tabela $4^{13}$.

\footnotetext{
13 Note que, para a estimação dos modelos econométricos, a variável de interesse (associação a cooperativas) foi interagida com dummies para cada macrorregião do País $(D N, D N E$, $D S E$ e DCO, tendo a região Sul como base).
} 
Figura 3. Mapa de Cluster Lisa para a variável de interesse (associação a cooperativas) em 2006

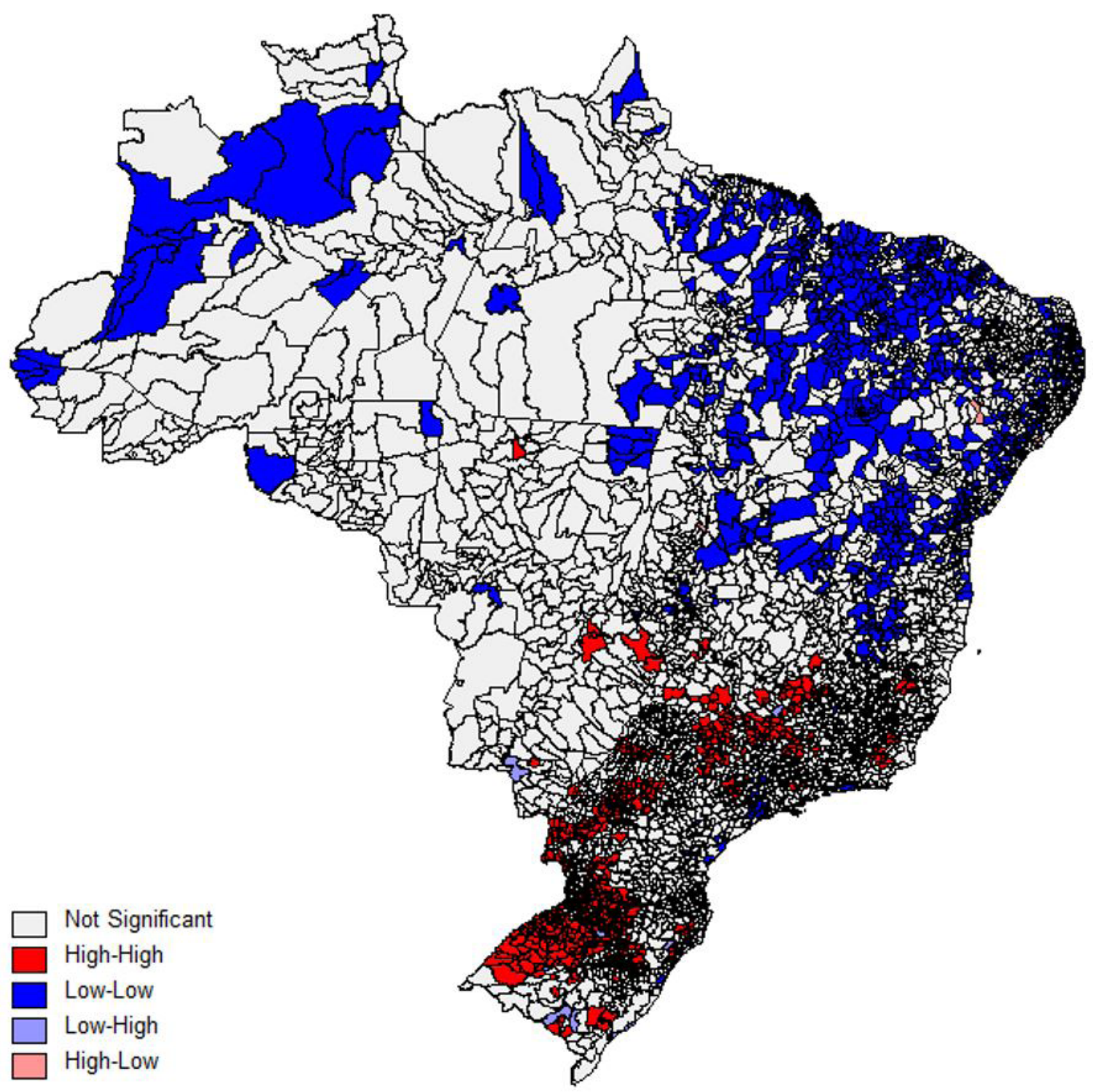

Fonte: Elaborada pelos autores.

De acordo com os resultados reportados na segunda coluna (modelo MQO), nota-se que todas as variáveis de controle foram estatisticamente significativas a $1 \%$, incluindo as dummies que captam regionalmente a taxa de associação a cooperativas. Entretanto, a verificação dos testes de diagnóstico revelou traços de dependência espacial, o que vai de acordo com a Aede realizada, da mesma forma que os resíduos também se apresentaram heterocedásticos e não normais. Assim, da maneira como foi estimado, o modelo MQO revelou-se mal especificado, impossibilitando a interpretação de seus coeficientes.
Visando expandir as referências acerca do tipo de autocorrelação espacial, foram apurados testes do Multiplicador de Lagrange para a defasagem $\left(\mathrm{ML}_{\mathrm{\rho}}\right)$ e para o erro autorregressivo $\left(\mathrm{ML}_{\lambda}\right)$ assim como suas versões robustas. Todos estes testes foram diferentes de zero estatisticamente, sugerindo, preliminarmente, que o modelo espacial de interesse possa ser dos tipos SAR, SEM, SDM ou SDEM.

Na busca pela obtenção do mais adequado entre os modelos sugeridos, optou-se pela aplicação do critério de Stakhovych \& Bijmolt (2009), que se baseia 
na comparação entre as estatísticas de Akaike fornecidas pelos diferentes modelos estimados, que utilizam matrizes de defasagem espaciais distintas. A escolha comporta o modelo que apresentar o menor valor de Akaike e que, ao mesmo tempo, seja capaz de eliminar o problema da dependência espacial.

Observando a Tabela 4, nota-se que foi feita a opção pelo modelo SAR, que, estimado por máxima verossimilhança ${ }^{14}$, foi capaz de controlar a dependência espacial a 5\% de significância, como pode ser visto pelo teste $\mathrm{ML}_{\rho}$. A estimação do modelo SAR também contou com correções para a heterocedasticidade por meio da matriz de variância e covariância robusta de White.

Para as demais variáveis, nota-se que os sinais dos coeficientes foram positivos para todas, excetuando terra, sendo o efeito positivo dos fatores produtivos similar na produção. Nota-se, ainda, que os resultados dos coeficientes das dummies DN, DNE e DCO seriam subestimados, enquanto o da dummy DSE seria superestimado, caso o modelo utilizado para reportar os resultados fosse estimado por MQO.

Deve-se salientar que uma das vantagens de utilizar a forma funcional Cobb-Douglas é a possibilidade de identificar os retornos à escala da função de produção por meio da soma direta das elasticidades dos fatores produtivos (Chambers, 1988). Nesse sentido, observou-se que, para a função estimada para o Brasil, a soma das elasticidades foi de 1,04, ou seja, o retorno da tecnologia utilizada se aproxima dos retornos constantes à escala (Tabela 4). Tal resultado é semelhante ao encontrado por Alves et al. (2012), que, com base nos microdados do Censo Agropecuário 2006, identificaram um retorno à escala próximo à unidade $(0,924)$, bem como por Helfand et al. (2015), que, utilizando dados do Censo Agropecuário 2006, agregados por grupos de área, obtiveram retorno à escala de $1,02^{15}$.

14 A princípio, o modelo SAR também foi estimado por GMM, buscando o controle para potenciais endogeneidades. Entretanto, o resultado obtido não eliminou o problema da autocorrelação espacial, o que implicou na impossibilidade de trabalhar com os resultados deste tipo de estimação.

15 Diferentemente deste trabalho, Alves et al. (2012) utilizam três fatores produtivos para representar a fronteira de produção do Brasil, quais sejam: gastos com trabalho, gastos com terra e gastos com insumos tecnológicos. Já Helfand et al. (2015) utilizaram terra, trabalho familiar, insumos intermediários comprados e estoque de capital (composto por máquinas, animais e árvores). Sendo assim, a pequena diferença encontrada para os retornos aos fatores produtivos pode ser devida às diferenças nas especificações do modelo em cada pesquisa.

\subsubsection{Efeitos nas regiões Sudeste, Centro-Oeste e Sul}

Os efeitos particionados das dummies estão dispostos nas três últimas colunas da Tabela 4, sendo todos estes efeitos estatisticamente significativos para todas as variáveis. De maneira geral, tem-se que o fato de o indivíduo, independentemente de sua forma jurídica, associar-se a cooperativas influenciou, positivamente, tanto de maneira direta o crescimento da produção agrícola em seu município, como indiretamente na produção agrícola dos municípios contíguos, nas regiões Centro-Oeste e Sudeste, em comparação com a região Sul do País (região base).

Isto posto, um aumento de $10 \%$ na taxa de associação a cooperativas, coeteris paribus, elevaria em $1,65 \%$ o VBP dos municípios do Centro-Oeste, havendo ainda um efeito nos municípios vizinhos da ordem de $0,09 \%$, o que culminaria em um efeito total na elevação em torno de 1,74\% do VBP. Quanto à região Sudeste, tal elevação levaria a um efeito de $0,42 \%$ no VBP dos municípios da região, com resultado de $0,02 \%$ nos municípios vizinhos, o que levaria a um efeito total de $0,44 \%$. Por sua vez, a categoria base, Sul, teria em seus municípios um aumento médio do VBP, coeteris paribus, da ordem de $0,8 \%$.

Em termos aproximados, com base nos valores da Tabela 1 e da Tabela 2, é possível afirmar que 10\% de elevação no contingente de associados a cooperativas impactaria positivamente em $\mathrm{R} \$ 596$ milhões, ou 0,61\%, do VBP das três regiões.

$\mathrm{Na}$ busca por elucidações acerca dos resultados, salienta-se que o sistema cooperativo tem notória relevância junto aos produtores de grãos, majoritariamente no Centro-Oeste e Sul do País. Neste sentido, segundo Zanon \& Saes (2010), significativa parcela da produção dos sojicultores (57\%) é entregue a cooperativas. Considerando, segundo os autores, que as menores propriedades produtoras de soja se concentram na região Sul, depreende-se a importância da participação dos produtores de soja nas cooperativas da região. De forma semelhante à sojicultura, $43 \%$ da produção de milho tem nas cooperativas canal de comercialização (Instituto Brasileiro de Geografia e Estatística, 2016).

Ainda segundo dados de Instituto Brasileiro de Geografia e Estatística (2016), no Sul e Centro-Oeste, principalmente, onde estão localizadas algumas das maiores cooperativas agropecuárias do País, em sua maioria, há ainda o arroz e o algodão, além do trigo, no Rio Grande 
Tabela 4. Estimativas do modelo sem e com controle espacial

\begin{tabular}{|c|c|c|c|c|c|}
\hline \multirow{2}{*}{ Variável } & \multirow{2}{*}{ MQO } & \multirow{2}{*}{ SAR } & \multicolumn{3}{|c|}{ Efeitos-SAR } \\
\hline & & & Direto & Indireto & Total \\
\hline \multirow{2}{*}{ Constante } & $0,4533^{* * *}$ & $0,2074^{* * *}$ & - & - & - \\
\hline & $(0,0380)$ & $(0,0502)$ & - & - & - \\
\hline \multirow{2}{*}{ trabalho } & $0,4102^{* * *}$ & $0,4051^{* * *}$ & $0,4054^{* * *}$ & $0,0216^{* * *}$ & $0,4270^{* * *}$ \\
\hline & $(0,0140)$ & $(0,0139)$ & {$[32,4649]$} & {$[6,4091]$} & {$[31,4563]$} \\
\hline \multirow{2}{*}{ terra } & $-0,2423^{* * *}$ & $-0,2425^{* * *}$ & $-0,2427^{* * *}$ & $-0,0130^{* * * *}$ & $-0,2556^{* * *}$ \\
\hline & $(0,0144)$ & $(0,0143)$ & {$[-17,3142]$} & {$[-5,9487]$} & {$[-16,9994]$} \\
\hline \multirow{2}{*}{ insumos } & $0,4466^{* * *}$ & $0,4281^{* * *}$ & $0,4284^{* * *}$ & $0,0229^{* * *}$ & $0,4512^{* * *}$ \\
\hline & $(0,0126)$ & $(0,0128)$ & {$[33,7585]$} & {$[6,5458]$} & {$[33,5825]$} \\
\hline \multirow{2}{*}{ capital } & $0,4413^{* * *}$ & $0,4439^{* * * *}$ & $0,4442^{* * *}$ & $0,0237^{* * *}$ & $0,4679^{* * *}$ \\
\hline & $(0,0136)$ & $(0,0135)$ & {$[32,5619]$} & {$[6,4608]$} & {$[31,8584]$} \\
\hline \multirow{2}{*}{$D N$} & $-0,0446^{* * *}$ & $-0,0506^{* * *}$ & $-0,0507^{* * *}$ & $-0,0027^{* * *}$ & $-0,0534^{* * *}$ \\
\hline & $(0,0123)$ & $(0,0123)$ & {$[-3,9638]$} & {$[-3,2767]$} & {$[-3,9568]$} \\
\hline \multirow{2}{*}{$D N E$} & $-0,0605^{* * *}$ & $-0,0657^{* * *}$ & $-0,0657^{* * *}$ & $-0,0035^{* * *}$ & $-0,0692^{* * *}$ \\
\hline & $(0,0073)$ & $(0,0073)$ & {$[-9,1106]$} & {$[-5,0006]$} & {$[-9,0195]$} \\
\hline \multirow{2}{*}{$D S E$} & $0,0415^{* * *}$ & $0,0336^{* * *}$ & $0,0336^{* * *}$ & $0,0018^{* * *}$ & $0,0354^{* * *}$ \\
\hline & $(0,0099)$ & $(0,0099)$ & {$[3,3574]$} & {$[3,1915]$} & {$[3,3700]$} \\
\hline \multirow{2}{*}{$D C O$} & $0,1716^{* * *}$ & $0,1650^{* * *}$ & $0,1651^{* * *}$ & $0,0088^{* * *}$ & $0,1739^{* * *}$ \\
\hline & $(0,0147)$ & $(0,0147)$ & {$[11,5876]$} & {$[5,9655]$} & {$[11,6702]$} \\
\hline \multirow{2}{*}{$\rho$} & - & $-0,0231^{*}$ & - & - & - \\
\hline & - & $(0,0964)$ & - & - & - \\
\hline \multicolumn{6}{|c|}{ Estatísticas de Testes do Modelo } \\
\hline $\mathrm{R}^{2}$ & 0,8709 & 0,8711 & - & - & - \\
\hline SC & $4.384,3800$ & - & - & - & - \\
\hline Jarque-Bera & $134.774,9440$ & - & - & - & - \\
\hline p-valor & $0,0000^{* * *}$ & - & - & - & - \\
\hline Koenker-Bassett & 152,6676 & - & - & - & - \\
\hline p-valor & $0,0000^{* * *}$ & - & - & - & - \\
\hline$I$ de Moran & 0,2359 & - & - & - & - \\
\hline p-valor & $0,0000^{* * *}$ & - & - & - & - \\
\hline ML $\rho$ & 50,8475 & 447,3830 & - & - & - \\
\hline p-valor & $0,0000^{* * *}$ & $0,0593^{*}$ & - & - & - \\
\hline MLג & 528,5852 & - & - & - & - \\
\hline p-valor & $0,0000^{* * *}$ & - & - & - & - \\
\hline$M L \rho^{*}$ & 7,7715 & - & - & - & - \\
\hline p-valor & $0,0053^{* * *}$ & - & - & - & - \\
\hline$M L \lambda^{*}$ & 485,5092 & - & - & - & - \\
\hline p-valor & $0,0000^{* * *}$ & - & - & - & - \\
\hline Matriz & $k-3$ & $k-3$ & - & - & - \\
\hline
\end{tabular}

Fonte: Elaborado pelos autores.

Obs: Desvio padrão entre parênteses e estatística Z entre colchetes. Nota: * Significativo a $10 \%$; ${ }^{* *}$ Significativo a $5 \%$; *** Significativo a $1 \%$. 
do Sul, como principais produtos cultivados por seus associados (Organização das Cooperativas Brasileiras, 2013). Quanto à pecuária, importantes cooperativas no Sul e Sudeste fazem a receptação e o processamento de leite e carne, esta última principalmente de frango e suínos. No que diz respeito à produção de leite, o Brasil é um dos maiores produtores mundiais, sendo que, de acordo com Chaddad (2007), até $40 \%$ de todo o leite captado era entregue a cooperativas.

Produtores que cultivam de cana-de-açúcar em São Paulo e café em Minas Gerais e Espírito Santo também estão entre aqueles que mais buscam cooperativas tendo em vista a obtenção de insumos e o escoamento de sua produção. Neste sentido, segundo Instituto Brasileiro de Geografia e Estatística (2016), 48\% do café produzido no País é entregue em cooperativas. Ademais, de acordo com Oñate \& Lima (2012), os produtores independentes são responsáveis por cerca de $30 \%$ da produção de cana-de-açúcar de São Paulo, fato que não diminui a relevância das cooperativas junto aos produtores independentes, já que, ainda segundo Oñate \& Lima (2012), também as cooperativas de crédito respondem por importante fonte de financiamento para os produtores de cana-de-açúcar.

Atrelados a estas cooperativas, produtores rurais teriam mais chances de usufruir dos benefícios destas organizações, tais como: i) maior integração vertical, visando à redução dos custos via aumento do poder de barganha na aquisição dos insumos; ii) economias de escala, dado o maior montante de produtos manejado pela cooperativa, o que culmina em maior posição de barganha na venda dos produtos ao mercado, em especial quando se trata de produtos perecíveis e commodities e iii) diluição do risco da atividade econômica pelas ações conjuntas, comuns a esse tipo de empreendimento (Sexton, 1986).

Concomitantemente, tendo em vista o bem-estar da sociedade de modo geral, as cooperativas agropecuárias seriam capazes de modificar o comportamento das firmas já existentes, pela sua capacidade de atenuar os efeitos adversos de uma estrutura de mercado concentrada. Entrando em um mercado específico, as cooperativas fariam com que tais firmas passassem a operar sob condições mais próximas à competição perfeita (Sexton, 1990).

Outro ponto relevante diz respeito ao impacto local dessas cooperativas. Em geral, elas obtêm a maioria dos insumos localmente. Como os cooperados geralmente são membros da comunidade, podem apoiar a compra desses insumos localmente (mesmo que sejam mais caros). Afinal, no longo prazo, espera-se que benefícios sociais e econômicos sejam gerados para a comunidade. Usando a mesma lógica, os consumidores podem comprar mais de suas cooperativas locais, especialmente se forem membros destas (Fulton \& Ketilson, 1992; Merrett \& Walzer, 2001).

Para além das questões meramente econômicas e produtivas, pode-se citar ainda o elevado nível de capital social existente, primordialmente na região Sul (Silva et al., 2003). Este capital está atrelado a projetos conjuntos que promovem a colaboração com vistas ao benefício mútuo de toda a sociedade. Tal característica impulsiona o movimento cooperativista, devendo ser desenvolvida e estimulada, via educação para a cooperação, também em outras regiões do País.

\subsubsection{Efeitos nas regiões Norte e Nordeste}

O efeito contrário ao Sudeste e ao Centro-Oeste pode ser constatado no Norte e Nordeste. Nestas regiões, a associação de mais 10\% de estabelecimentos a cooperativas nos próprios municípios acomete, diretamente, o valor da produção agrícola total com uma queda de 0,51\% na primeira região e $0,65 \%$ na segunda, coteris paribus. Concomitantemente, afeta indiretamente os municípios vizinhos, gerando queda de $0,03 \%$ no Norte e de $0,04 \%$ no Nordeste.

Deste modo, uma elevação de $10 \%$ de associados nestas regiões diminuiria o VBP em R $\$ 188$ milhões, ou $0,65 \%$. Assim, o resultado combinado, considerando o efeito da variação no número de cooperados em todas as regiões brasileiras, seria positivo em $\mathrm{R} \$ 408$ milhões.

$\mathrm{O}$ efeito negativo do cooperativismo no Norte e Nordeste brasileiros, quando comparados à região Sul, pode ser em muito explicado pelas experiências de implantação de organizações mutualísticas.

Historicamente, contrastes profundos marcaram o cooperativismo nordestino, com empreendimentos cooperativos sendo criados por grupos de poder locais - latifundiários - visando ocupar cargos diretivos e a exercer influência perante os pequenos produtores, ampla maioria dos cooperados (Rios, 1973).

Além disso, tanto o Norte quanto o Nordeste se ressentem da ausência de políticas efetivas de desenvolvimento, o que se reflete na dificuldade de 
muitas cooperativas em acessar recursos e estrutura que os possibilitem aprimorar práticas de gestão e produção. Alia-se a isso a falta de planejamento e de capacidade de investimento e acaba por se defrontar com cooperativas com baixos níveis de competitividade e capitalização, principalmente as de menor porte (Silva et al., 2003).

Entretanto, a busca pela revitalização do cooperativismo nestas regiões está em curso, num esforço que envolve universidades, entidades de representação e órgãos públicos e privados na construção de canais para a discussão do modelo mais adequado às realidades locais, com foco na sustentabilidade econômica e social, passando pela ênfase na capacitação dos quadros de associados e diretivos das cooperativas e associações (Silva et al., 2003).

Especificamente quanto à região Nordeste, é importante salientar que, apesar dos resultados negativos, ela é dotada de uma riqueza associativa que suplanta a forma jurídica, sendo a ação coletiva empreendida por meio de associações formais e informais, de natureza mutualística solidária que, por vezes, são ignoradas pelas estatísticas oficiais, não sendo, por este motivo, menos importantes enquanto modelos locais de cooperação, com efeitos positivos sobre a produção de seus membros. O apoio a estes empreendimentos, como etapas pré-cooperativas que, segundo Rios (1973), visam ao aprendizado na coordenação de esforços e ao robustecimento do capital social entre seus integrantes, pode permitir o desenvolvimento das capacidades financeira e de gestão, necessárias para que façam ainda mais a diferença na produção e na qualidade de vida no meio rural destas regiões.

\section{Conclusões}

$\mathrm{O}$ apoio a ações que visem divulgar e fortalecer o cooperativismo no Brasil deve se basear em estudos que mensurem seu real impacto junto aos associados e às economias regional e nacional. Neste sentido, é importante que haja medidas mais precisas do retorno da associação a cooperativas, buscando indicações que possam esclarecer melhor se, de fato, a associação a cooperativas tem a capacidade de elevar o rendimento econômico do estabelecimento agropecuário.
Assim, a metodologia proposta neste trabalho permitiu lançar luz sobre um tema ainda pouco explorado na literatura brasileira: a influência das cooperativas na produção agropecuária das regiões brasileiras. Utilizando de um modelo parcimonioso e contando com correções espaciais, constatou-se que o fato de estar associado a cooperativas foi positivo à produção dos agricultores das regiões Sudeste, Centro-Oeste e Sul. Por sua vez, pertencer a cooperativas no Norte e Nordeste causou impacto negativo na produção dos agricultores, quando comparados àqueles da região Sul (região base).

Os resultados também evidenciam que a difusão do modelo cooperativista pelo País pode não ser prova suficiente de sua viabilidade como organização e de sua influência positiva junto às comunidades nas quais se insere. Experiências malsucedidas e crises vivenciadas pelas cooperativas ao longo dos últimos anos, além do seu impacto pouco efetivo em regiões onde a tradição dos precursores do movimento não é tão difundida, mostram ainda haver um longo caminho para que o Brasil tenha taxas de cooperados no meio rural tão elevadas quanto as de diversos países do mundo, condizentes com os propagados benefícios que estas organizações podem gerar.

No entanto, deve-se salientar que, nas regiões Nordeste e Norte, o cooperativismo pode não ser a forma organizacional mais adequada ao contexto de desenvolvimento dos movimentos coletivos. Nestes locais, os grupos informais, as associações, os sindicatos rurais e outros tipos de empreendimentos associativos podem ser os mais indicados, gerando resultados positivos pela congregação dos produtores rurais. $\mathrm{O}$ aprimoramento das capacidades econômicas e administrativas de tais empreendimentos torna-se relevante na medida em que tais empreendimentos atuam, muitas vezes, como "ensaios pré-cooperativos". Ou seja, preparam seus membros para alçar voos mais altos em organizações coletivas com coordenação e gestão mais complexas, como as próprias organizações cooperativas.

Por fim, considera-se que as estimativas apresentadas neste trabalho sejam úteis para os formuladores de políticas públicas, já que medem o desempenho das cooperativas como fonte alternativa de crescimento e desenvolvimento econômico nas comunidades e na oferta de bens e serviços. Ainda, os órgãos de representação do setor cooperativista podem utilizar-se dos resultados de estudos desta natureza para mostrar a importância 
da participação das cooperativas na economia e, assim, justificar o apoio a investimentos direcionados à propagação da educação cooperativista e ao desenvolvimento destas sociedades de pessoas.

\section{Agradecimentos}

Os autores agradecem ao Conselho Nacional de Desenvolvimento Científico e Tecnológico (CNPq), à Coordenação de Aperfeiçoamento de Pessoal de Nível Superior (Capes) e à Fundação de Amparo à Pesquisa do Estado de Minas Gerais (Fapemig) pelo suporte financeiro para a realização da pesquisa.

\section{Referências}

Almeida, E. S. (2012). Econometria espacial aplicada. Campinas, SP: Editora Alínea.

Alves, E., Souza, G. D. S., \& Rocha, D. D. P. (2012). Lucratividade da agricultura. Revista de Política Agrícola, 21(2), 45-63.

Anselin, L. (1995). Local Indicators of Spatial AssociationLISA. Geographical Analysis, 27(2), 93-115.

Anselin, L. (2013). Spatial econometrics: methods and models. Boston: Springer Science \& Business Media.

Barker, R., \& Stanton, B. F. (1965). Estimation and aggregation of firm supply functions. Journal of Farm Economics, 47(3), 701-712.

Baumont, C. (2004). Spatial Effects in housing price models: do house prices capitalize urban development policies in the agglomeration of Dijon (1999)? Bourgogne: Mimeo., Université de Bourgogne.

Baumol, W. J. (1977). Economic theory and operations analysis. London: Prentice-Hall.

Belik, W. (2015). A heterogeneidade e suas implicações para as Políticas Públicas no Rural Brasileiro. Revista de Economia e Sociologia Rural, 53(1), 9-30.

Bialoskorski Neto, S. (2000). Agribusiness Cooperativo. In D. Zylbersztajn \& M. F. Neves (Orgs.), Economia e gestão dos negócios agroalimentares: indústria de alimentos, indústria de insumos, produção agropecuária, distribuição (pp. 235-253). São Paulo: Pioneira.

Bialoskorski Neto, S. (2005). Cooperativas agropecuárias do Estado de São Paulo: uma análise da evolução na década de 90 (vol. 35, pp. 1-11). São Paulo: Informações Econômicas.
Bonus, H. (1986). The cooperative association as a business enterprise: a study in the economics of transactions. Journal of Institutional and Theoretical Economics (JITE)/ Zeitschrift fur die Gesamte Staatswissenschaft, 142(2), 310-339.

Buainain, A. M., González, M. G., Souza Filho, H. M. F., \& Vieira, A. C. P. (2007). Alternativas de financiamento agropecuário: experiências no Brasil e na América Latina. Brasília: Instituto Interamericano de Cooperação Agrícola.

Castro, L. S., Almeida, E. S., \& Lima, J. E. (2015). A convergência espacial da produtividade de soja no Brasil: o caso das regiões Centro-Oeste e Sul. Revista Espacios, 36, 1-20.

Castro, N. (2002). Custos de transporte e produção agropecuária no Brasil, 1970-1996. Agricultura em São Paulo, 49(2), 87-109.

Cazzuffi, C. (2013). Small scale farmers in the market and the role of processing and marketing cooperatives: A case study of Italian dairy farmers (Tese de doutorado). University of Sussex, Sussex.

Chaddad, F. R. (2007). Cooperativas no agronegócio do leite: mudanças organizacionais e estratégicas em resposta à globalização. Organizações Rurais $\mathcal{E}$ Agroindustriais, 9(1), 69-78.

Chambers, R. G. (1988). Applied Production Analysis: a dual approach. Cambridge University Press, Cambridge.

Cobb, C. W., \& Douglas, P. H. (1928). A theory of production. The American Economic Review, 18(1), 139-165.

Coelli, T. J., Rao, D. S. P., \& Battese, G. E. (1998). An introduction to efficiency and productivity analysis. Boston: Kluwer Academic Publishers.

Curi, W. F. (1997). Eficiência e fontes de crescimento da agricultura mineira na dinâmica de ajustamento da economia brasileira (Tese de doutorado). Universidade Federal de Viçosa, Viçosa.

Duarte, L. M. G. (1986). Capitalismo e Cooperativismo no RGS: o cooperativismo empresarial e a expansão do capitalismo no setor rural do Rio Grande do Sul. Porto Alegre: L\&PM/ ANPOCS.

Fundação Getúlio Vargas - FGV, \& Instituto Brasileiro de Economia - IBRE. (2010). Quem produz o que no campo: quanto e onde II. Censo Agropecuário 2006. Resultados: Brasil e regiões. Brasília: CNA.

Florax, R. J. G. M., Folmer, H., \& Rey, S. J. (2003). Specification searches in spatial econometrics: The relevance of Hendry's methodology. Regional Science and Urban Economics, 33(5), 557-579.

Folsom, J. (2003). Measuring the economic impact of cooperatives in Minnesota. Washington, DC: United States Department of Agriculture, Rural Business-Cooperative Service. (RBS Research Report, 200). 
Fulton, M. E., \& Ketilson, L. H. (1992). The role of cooperatives in communities: Examples from Saskatchewan. Journal of Agricultural Cooperation, 7, 15-42.

Hansmann, H. (1988). Ownership of the Firm. Journal of Law Economics and Organization, 4(2), 267-304.

Hansmann, H. (1996). The Ownership of Enterprise. Cambridge: The Belknap Press of Harvard University Press.

Hayami, Y., \& Ruttan, V. W. (1971). Agricultural Development: an international perspective. Baltimore: The Johns Hopkins Press.

Helfand, S., Pereira, M., \& Soares, W. (2014). Pequenos e médios produtores na agricultura brasileira: situação atual e perspectivas. In A. M. Buainain, E. Alves, J. M. Silveira \& Z. Navarro. O mundo rural no Brasil do século XXI: a formação de um novo padrão agrário e agrícola. Brasília/Campinas: Embrapa/Instituto de Economia da Unicamp.

Helfand, S. M., \& Brunstein, L. F. (2001). The changing structure of the Brazilian agricultural sector and the limitations of the 1995/96 agricultural census. Revista de Economia e Sociologia Rural, 39(3), 179-203.

Helfand, S. M., Magalhães, M. M., \& Rada, N. E. (2015, July 26-28). Brazil's Agricultural Total Factor Productivity Growth by Farm Size. In Annals of 2011 AAEA Annual Meeting, San Francisco, CA: Agricultural \& Applied Economics Association.

Humphrey, T.M. (1997). Algebraic production functions and their uses before Cobb-Douglas. Economic QuarterlyFederal Reserve Bank of Richmond, 83(1), 51-83.

Instituto Brasileiro de Geografia e Estatística - IBGE. (2016). Sistema IBGE de Recuperação Automática: SIDRA. Brasília. Recuperado em 12 de dezembro de 2016, de http: / / www.sidra.ibge.gov.br.

Jardine, S. L., Lin, C. Y. C., \& Sanchirico, J. N. (2014). Measuring benefits from a marketing cooperative in the copper river fishery. American Journal of Agricultural Economics, 96(4), 1084-1101.

Kageyama, A. A., Bergamasco, S. M. P. P., \& Oliveira, J. T. A. (2013). Uma tipologia dos estabelecimentos agropecuários do Brasil a partir do censo de 2006. Revista de Economia e Sociologia Rural, 51(1), 105-122.

Lesage, J. P. (2008). An introduction to spatial econometrics. Revue d'Economie Industrielle, 123(3), 19-44.

Lesage, J. P., \& Pace, R. K. (2009). Introduction to spatial econometrics. Boca Raton: CRC Press.

McNamara, K. T., Fulton, J., \& Hine, S. (2001). The Economic impacts associated with locally owned agricultural cooperatives: a comparison of the Great Plains and the Eastern Cornbelt. In Annals of 2001 Annual Meeting. Las Vegas, Nevada: NCERA-194 Research on Cooperatives.
Merrett, C., \& Walzer, N. (2001). A cooperative approach to local economic development. Connecticut: Quorom Books.

Moran, P. A. P. (1948). The interpretation of statistical maps. Journal of the Royal Statistical Society. Series B. Methodological, 10(2), 243-251.

Namorado, R. (2013). O essencial sobre cooperativas. Lisboa: Leya.

Nerlove, M., \& Bachman, K. L. (1960). The analysis of changes in agricultural supply: problems and approaches. Journal of Farm Economics, 42(3), 531-554.

Neves, M. C. R., \& Braga, M. J. (2015). Eficiência financeira e operacional em cooperativas participantes do Programa de Capitalização de Cooperativas Agropecuárias (ProcapAgro). Organizações Rurais \& Agroindustriais, 17(3), 285-301.

Oñate, C. A., \& Lima, R. A. S. (2012). Importância das cooperativas de crédito para fornecedores de cana-deaçúcar: um estudo de caso. Revista de Economia e Sociologia Rural, 50(2), 301-318.

Organização das Cooperativas Brasileiras - OCB. (2012). Panorama do cooperativismo brasileiro - 2011. Relatório da gerência de monitoramento. Brasília. Recuperado em 10 de outubro de 2016, de www.ocb.org.br/gerenciador / ba / arquivos/panorama_do_cooperativismo_brasileiro_2011.pdf

Organização das Cooperativas Brasileiras - OCB. (2013). Cooperativismo Agropecuário: Câmara Temática de Insumos Agropecuários - 2013. Recuperado em 12 de dezembro de 2016, de http:/ / www.agricultura.gov.br/arq_editor/ file/camaras_tematicas/Insumos_agropecuarios/7RO/ app_ocb

Organização das Cooperativas Brasileiras - OCB. (2015). Relatório OCB 2014: o que nos torna cooperativistas. Recuperado em 30 de setembro 2016, de http: / / www. brasilcooperativo.coop.br/arquivos/publica/relatorio_ OCB_2014_web.zip

Organização das Cooperativas Brasileiras - OCB. (2017). Agenda Institucional do Cooperativismo: Edição 2017. Recuperado em 03 de outubro de 2017, de http: / / www. ocb.org.br/arquivos/Publicacoes/agenda_institucional.pdf

Pinho, D. B. (1996). Lineamento da legislação cooperativa brasileira (Manual de Cooperativismo, v. 3). São Paulo, CNPq.

Pinho, D. B. (1992). O Pensamento cooperativo e o cooperativismo brasileiro (Manual de Cooperativismo, v. 1). São Paulo: CNPq.

Presno, N. B. (2001). As cooperativas e os desafios da competitividade. Estudos Sociedade e Agricultura, 17, 119-144.

Putnam, R. D. (1995). Bowling alone: America's declining social capital. Journal of Democracy, 6(1), 65-78.

Rios, G. S. L. (1973). Pré-cooperativismo: etapa queimada. In J. Uwe (Org.), A problemática cooperativista 
no desenvolvimento econômico (pp. 315-347). São Paulo: Fundação Friedrich Naumann.

Rodrigo, M. F. (2012). Do cooperatives help the poor? Evidence from Ethiopia. In Annals of Agricultural and Applied Economics Association's (AAEA) annual meeting. Seattle, Washington: Agricultural \& Applied Economics Association.

Sexton, R. J. (1986). Cooperatives and the forces shaping agricultural marketing. American Journal of Agricultural Economics, 68(5), 1167-1172.

Sexton, R. J. (1990). Imperfect competition in agricultural market and the role of cooperatives: a spatial analysis. American Journal of Agricultural Economics, 72(3), 709-720.

Sexton, R. J., \& Iskow, J. (1988). Factors critical to the success or failure of emerging agricultural cooperatives (vol. 88, no. 3). Davis: Division of Agriculture and Natural Resources, University of California.

Sharples, J. A. (1969). The representative farm approach to estimation of supply response. American Journal of Agricultural Economics, 51(2), 353-361.

Silva, E. S., Salomão, I. L., McIntyre, J. P., Guerreiro, J., Pires, M. L. L. S., Albuquerque, P. P., Bergonsi, S., \& Vaz, S. C. (2003). Panorama do cooperativismo brasileiro: história, cenários e tendências. Revista uniRcoop, 1(2), 75-102.

Staatz, J. M. (1987). Farmers' incentives to take collective action via cooperatives: A transaction-cost approach. In J. S. Royer (Ed.), Cooperative theory: New approaches (pp.
87-107). Washington, DC: U.S. Department of Agriculture. (Agricultural Cooperative Service Report, 18).

Stakhovych, S., \& Bijmolt, T. H. A. (2009). Specification of spatial models: A simulation study on weights matrices. Papers in Regional Science, 88(2), 389-408.

Uzea, N., \& Duguid, F. (2015). Challenges in conducting a study on the economic impact of cooperatives. In M. J. Bouchard, \& D. Rousselière (Eds.), The weight of the social economy: An international perspective (Vol. 6, pp. 251-276). Brussels: P.I.E. Peter Lang.

Valentinov, V. (2007). Why are cooperatives important in agriculture? An organizational economics perspective. Journal of Institutional Economics, 3(01), 55-69.

Zanon, R. S., \& Saes, M. S. M. (2010). Soybean production in Brazil: main determinants of property sizes. In Proceedings of the 4th International European Forum on System Dynamics and Innovation in Food Networks (pp. 292-306). Germany: University of Bonn.

Zeuli, K., Lawless, G., Deller, S., Cropp, R., \& Hughes, W. (2003). Measuring the economic impact of cooperatives: results from Wisconsin, United States. Washington, D.C.: Department of Agriculture, Rural Business-Cooperative Service. (RBS Research Report, 196).

Zeuli, K., \& Deller, S. (2007). Measuring the local economic impact of cooperatives. Journal of Rural Cooperation, 35(1), 1-17.

Zeuli, K., \& Radel, J. (2005). Cooperatives as a community development strategy: Linking theory and practice. The Journal of Regional Analysis \& Policy, 35(1), 43-54. 